\title{
An assessment of current fertiliser practices in New Zealand hill country
}

\author{
D.C. EDMEADES, R.M. McBRIDE and M. GRAY \\ agKnowledge Ltd, PO Box 9147, Hamilton 3240, New Zealand \\ doug.edmeades@agknowledge.co.nz
}

\begin{abstract}
In the last decade major reviews on the phosphorus (P), potassium $(\mathrm{K})$ and sulphur $(\mathrm{S})$ nutrient requirements of clover-based pastures in New Zealand have been completed. This has resulted in adjustments to the $\mathrm{P}, \mathrm{K}$ and $\mathrm{S}$ pasture production functions and some changes to the critical levels for soil tests, and modifications to our interpretation of some soil tests such as Organic S and Reserve K. Applying this new information to New Zealand's hill country pastoral soils, using case studies, suggests that there is considerable unrealized potential to increase productivity.
\end{abstract}

Keywords: critical levels, economics, fertiliser, pasture, phosphorus, potassium, soil fertility, soil tests, sulphur

\section{Key messages}

- There have been changes in our understanding and interpretation of the soil $\mathrm{K}$ and $\mathrm{S}$ tests

- Fertiliser P advice is best made on the basis of economic outcome

- Applying this information and approach indicates that there is considerable potential to increase the productivity of hill country.

\section{Introduction}

The Government has set the primary sector an aspirational goal to increase productivity by $25 \%$ by the year 2025. It is reasonable to ask; how can the fertiliser industry and the other consultants involved in offering fertiliser advice to farmers, contribute to this goal?

In the last decade major reviews have been published on the nutrient requirements phosphorus $(\mathrm{P})$, potassium $(\mathrm{K})$ and sulphur $(\mathrm{S})$ nutrient requirements of cloverbased pastures in New Zealand. This has resulted in adjustments to the $\mathrm{P}, \mathrm{K}$ and $\mathrm{S}$ pasture production functions and some changes to the critical levels for soil tests, and modifications to the interpretation of some soil tests such as Organic S and Reserve K (Edmeades et al. 2005; 2006; 2010).

These revised criteria are used to assess the current status of the soil fertility of NZ hill country pastures using information and case studies from agKnowledge Ltd clients.

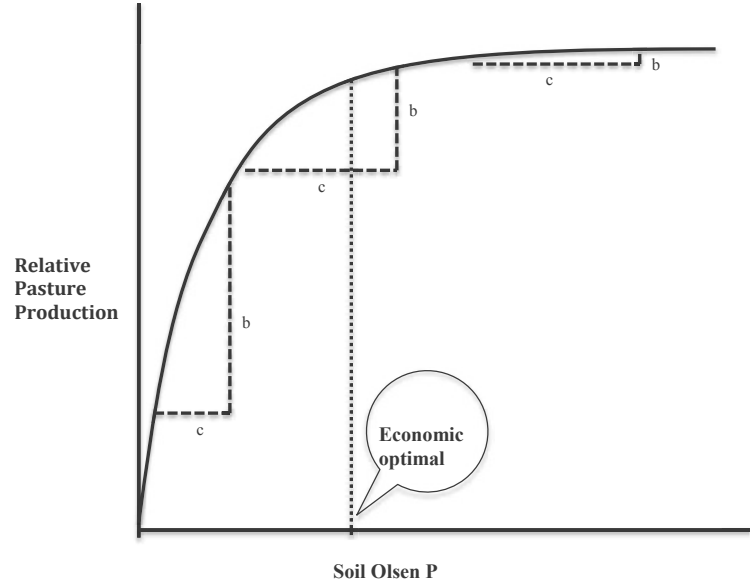

Figure 1 Schematic of the relationship between pasture production and Olsen $\mathrm{P}$ showing the economic optimal Olsen $P$ when the financial benefits (b) of applying fertiliser $P$ are equal to the costs (c) of applying fertiliser.

\section{Optimal soil test levels} Economic optimal Olsen $P$

The cost of the major nutrients required on New Zealand hill country pastures, based on current prices, are $\mathrm{P}(\$ 2.72 / \mathrm{kg} \mathrm{P}), \mathrm{K}(\$ 1.40 / \mathrm{kg} \mathrm{K})$ and $\mathrm{S}(\$ 0.77 / \mathrm{kg}$ $\mathrm{S})$. Thus, $\mathrm{P}$ is not only the major driver of the pasture production in our clover-based pastoral systems - it is also the most expensive nutrient. One approach, therefore, in rationalizing fertiliser inputs is to bring all the other soil nutrients, (in particular $\mathrm{K}$ and $\mathrm{S}$, but also magnesium $(\mathrm{Mg})$ and the trace element molybdenum (Mo) is some cases), to there biological optimum levels (to achieve maximum production) and then optimise the soil P level (Olsen P) for maximum economic return (profit) in the long-term (5-10 years).

The process of determining the economic optimal Olsen P can be understood with reference to Figure 1 , which shows schematically the production function relating plant available $\mathrm{P}(\mathrm{Olsen} \mathrm{P})$ to the relative pasture production. The economic optimal is defined where the cost (c) of applying fertiliser equals the financial benefit (b) accruing from the additional pasture grown (i.e. benefits (b) = costs (c) in Figure 1).

The major factor affecting the economic optimal Olsen $\mathrm{P}$ is the biological efficiency of the farm (dollars generated $/ \mathrm{kg}$ DM produced) and a good measure of this internal efficiency is the gross margin (GM) 


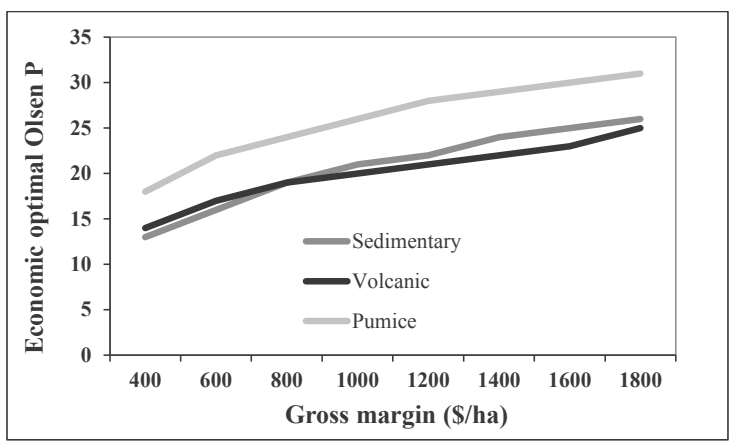

Figure 2 Relationship between gross margin (\$/ha) and the economic optimal Olsen $\mathrm{P}$ for three most important soil groups. (Assumptions: Topography, Easy Hill Country; Soil K = 7 MAF Quick test units; Extractable Organic Sulphur $=10$; gross margin = $\$ 100 /$ su; cost of $\mathrm{P}, \mathrm{K}$ and $\mathrm{S}$ as above; transport and spreading $=\$ 100 /$ tonne $)$.

defined as: the gross income minus the variable costs (the costs which are related to the number of animals), which includes; animal health, supplements, shearing costs and electricity. In contrast, the effects of fertiliser cost and transport and spreading have relatively minor effects on the economic optimal Olsen P.

The generic relationships between the economic optimal Olsen P and farm GM (\$/ha) for the three major soil groups, for a given set of input parameters, are shown in Figure 2, derived using the econometric model Overseer 3 (Metherell 1994).

The economic optimal Olsen P increases as the gross margin increases and is affected by soil order because the production functions relating Olsen $\mathrm{P}$ to relative pasture yields are slightly different for the different groups (Edmeades et al. 2006).

Given that the gross margin is the major determinant of the economic optimal Olsen $\mathrm{P}$ it is sensible, when developing a fertiliser plan, to divide the farm into blocks based on their actual, or planned, or potential productivity, and taking into account the soil group (see Case Studies later). This process should take into account the long-term farm goals, trends in future gross margins and any proposed changes in stock policies. For this purpose a farm consultant may deploy other tools such as Farmax as part of the decision making process.

Fertiliser P, K S is normally applied once a year and hence decisions regarding fertiliser policies and inputs are typically visited annually. Once the economic optimal Olsen P is established for a given block it will only need to be revised if there a major changes that affect the annual gross margin. Note that given the errors associated with estimated the economic Olsen P and the actual measurement of Olsen $\mathrm{P}$, it is pragmatic to think in terms of the range in economic Olsen $\mathrm{P}$ for a given block, as illustrated in the Case Studies (see later).

\section{Agronomic optimal soil $\mathrm{K}$ and $\mathrm{S}$ levels}

The review of all the $\mathrm{K}$ trials on New Zealand pastures (Edmeades et al. 2010) showed that the biological optimal $\mathrm{K}$ levels for all soil groups, including the sedimentary soils, was in the range 7-10 Quick Test units (QTK). Importantly, the ability of soil QTK to predict relative pasture production was not enhanced by including a measure of Reserve $\mathrm{K}$ (normally referred to as the TBK test), even on sedimentary soils. This test therefore has little value for determining the ability of soil to provide plant available $\mathrm{K}$.

A new understanding of the meaning and hence importance of the two soil tests for plant available $S$ emerged from the $S$ review (Edmeades et al. 2005). Sulphate S makes up a very small part of the plant available $\mathrm{S}$ pool $(<5 \%)$. Furthermore, it is extremely variable, mainly as a result of leaching events. For these reasons it has very little value as the basis for determining the $\mathrm{S}$ status of soils. The mineralisable organic S pool (referred to as the Organic $\mathrm{S}$ test) contributes about $95 \%$ of the available $\mathrm{S}$ in the soil. It is not subject to leaching and hence is a more robust measure of the soil $\mathrm{S}$ status. The biological optimal range is $10-12$. It is noted, however, that some soils, those under low rainfall $(<1000 \mathrm{~mm})$, cannot accumulate sufficient organic matter under pasture, such that the organic S levels can reach or exceed 10-12. Such soils will, therefore, always need external additions of fertiliser $\mathrm{S}$.

\section{Lime}

Lime may be required and this can also be determined based on the likely economic benefit (Edmeades et al. 1985). Given current costs and prices, it is always economic when ground spreading lime on cloverbased pastures, to increase the soil $\mathrm{pH}$ to the biological optimal range 5.8-6.0, noting that high optimal $\mathrm{pH}$ levels are required for some specialist legumes such as lucerne. However, most pastoral soils in New Zealand to which lime can be ground-spread have $\mathrm{pH}$ levels > 5.5. Pasture response to liming to the biological optimal $\mathrm{pH}$ for clover-based pastures (5.8-6.0) in such cases are small (0-5\%, see Edmeades et al. 1985), relative to correcting nutrient deficiencies and hence liming is only considered when all the optimal nutrient levels have been achieved.

The situation is different when aerial application of liming is necessary, as is the case in most hill country. Because of the greater on-ground costs, the economic optimal soil $\mathrm{pH}$ for aerial application of lime on clover pastures is currently about 5.5-5.6. If soil $\mathrm{pH}$ levels are below 5.5-5.6, (say < 5.3), liming is essential, together with nutrient inputs to optimise pasture production.

\section{Results}

Amongst agKnowledge Ltd clients few farms presented 

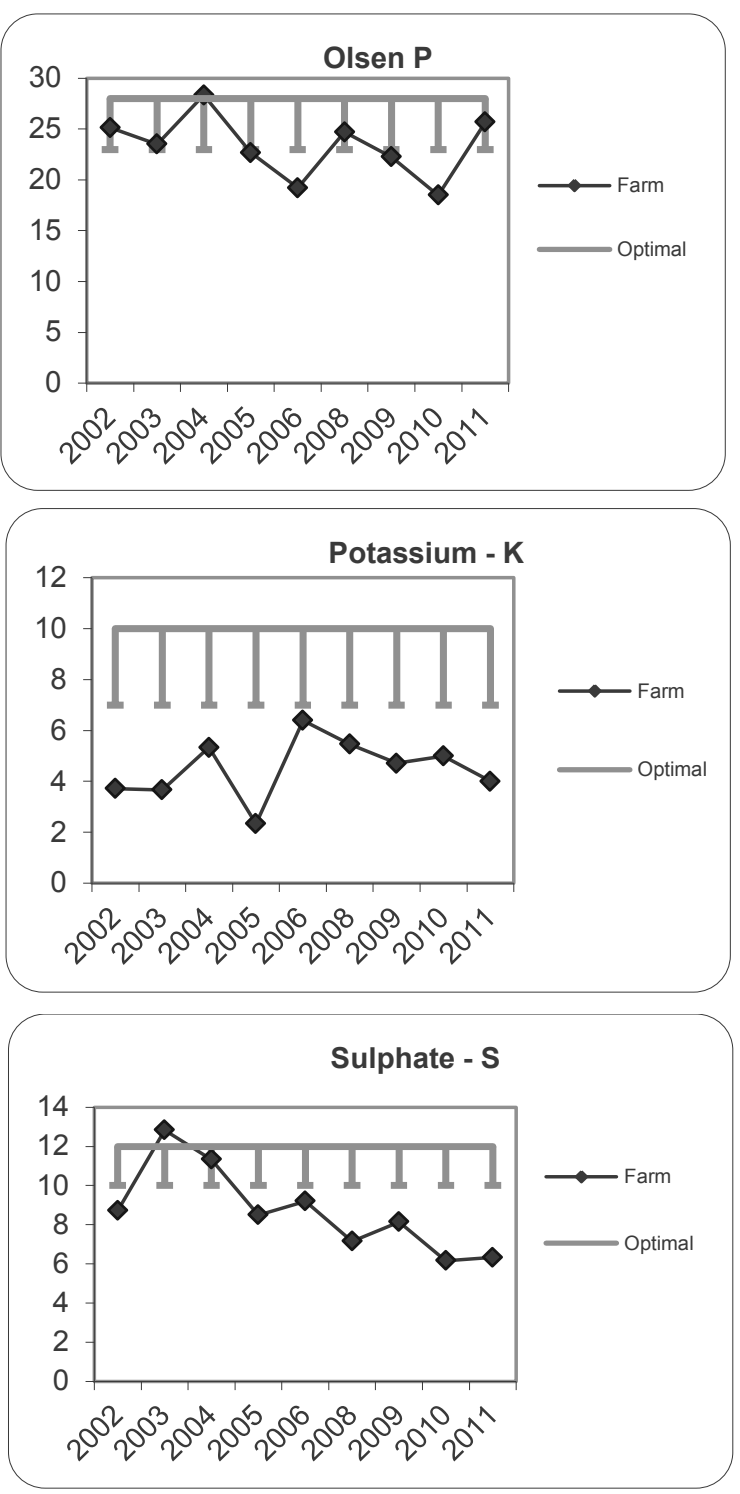

Figure 3 Changes in soil Olsen $\mathrm{P}(\mu \mathrm{g} / \mathrm{ml}$ soil), soil $\mathrm{K}(\mathrm{MAF}$ Quick Test Units) and sulphate sulphur-S $(\mu \mathrm{g} / \mathrm{g}$ in soil) over time, relative to the optimal ranges (grey-scale bands), on a mixed drystock farm in Southland.

with optimal soil fertility. Over the past 4 years detailed fertiliser plans have been developed for 790 farms of which only two required no capital fertiliser (i.e. they were at optimal nutrient levels). There is normally one or a combination of deficiencies of the major nutrients and the frequency is $\mathrm{K}>\mathrm{S}>\mathrm{P}$. Some cases of Mo deficiency have been noted and sometimes a liming program is justified. The case studies below are representative of the typical soil fertility problems that arise in hill country.

For each of these case studies the relevant historical soil tests are shown, indicating the soil fertility of the farms, together with a brief commentary of the salient points that result from this analysis. Complementing the soil testing information, pastures were assessed visually and clover-only samples collected for analysis. Normally the likely benefit (predicted increase in pasture production based on soil test pasture production functions) from the capital fertiliser program is provided to give the farmer confidence. In some cases the actual increases in farm production are recorded.

\section{Case Studies}

\section{Mixed sheep-deer-beef}

This Southland mixed drystock farm is on a sedimentary soil (Beef + Lamb land class 6, soil pH 6.0), running 12 stock units/ha with a gross margin of $\$ 1500 /$ ha. The trends in the historical soil $\mathrm{P}, \mathrm{K}$ and sulphate $\mathrm{S}$ levels over time, relative to the economic optimal Olsen $\mathrm{P}$ range and the biologically optimal ranges for $\mathrm{K}$ and $\mathrm{S}$, are shown below (Figure 3). For the sake of brevity the soil magnesium $(\mathrm{Mg})$, sodium $(\mathrm{Na})$ and $\mathrm{pH}$ levels were in their respective optimal ranges and are not shown.

The historical soil test data show that while adequate fertiliser P had been applied in the past, the whole farm was, and had been for some time, extremely $\mathrm{K}$ and $\mathrm{S}$ deficient. Note that soil organic $\mathrm{S}$, the largest and most important pool of available soil S was not measured. There appears to be reluctance in the industry to make use of this more reliable soil $\mathrm{S}$ test.

The remedial policy recommended in this case was to withhold P inputs and divert the fertiliser expenditure into capital inputs of $\mathrm{K}$ and $\mathrm{S}$. No lime was required because the average soil $\mathrm{pH}$ was 6.0. It was predicted based on the $\mathrm{K}$ and $\mathrm{S}$ production functions that the likely increase in the annual pasture production in this case would be between $10-20 \%$.

\section{Sheep and beef}

This west Southland sheep and beef farm has two land classes; a developed block (Beef + Lamb land class 2) and a hill block (Beef + Lamb land class 5), both on sedimentary soils. The trends in the soil P, K and S (both sulphate and organic S), over time, relative to the economic optimal Olsen P ranges, and the biologically optimal ranges for $\mathrm{K}$ and $\mathrm{S}$, are shown below (Figure 4) and, as before, it is not necessary to show the soil $\mathrm{Mg}$, $\mathrm{Na}$ and $\mathrm{pH}$ levels because they were optimal.

The two blocks have different actual and potential carrying capacities and for this reason there are two economic optimal soil Olsen $\mathrm{P}$ ranges, reflecting the difference in gross margin. Both blocks were below the respective economic optimal Olsen $\mathrm{P}$ ranges, particularly so for the potentially highly productive, developed flats. In this case the soil sulphate levels were variable, as is often the case with this test, and the more stable and important organic $\mathrm{S}$ test indicated $\mathrm{S}$ 

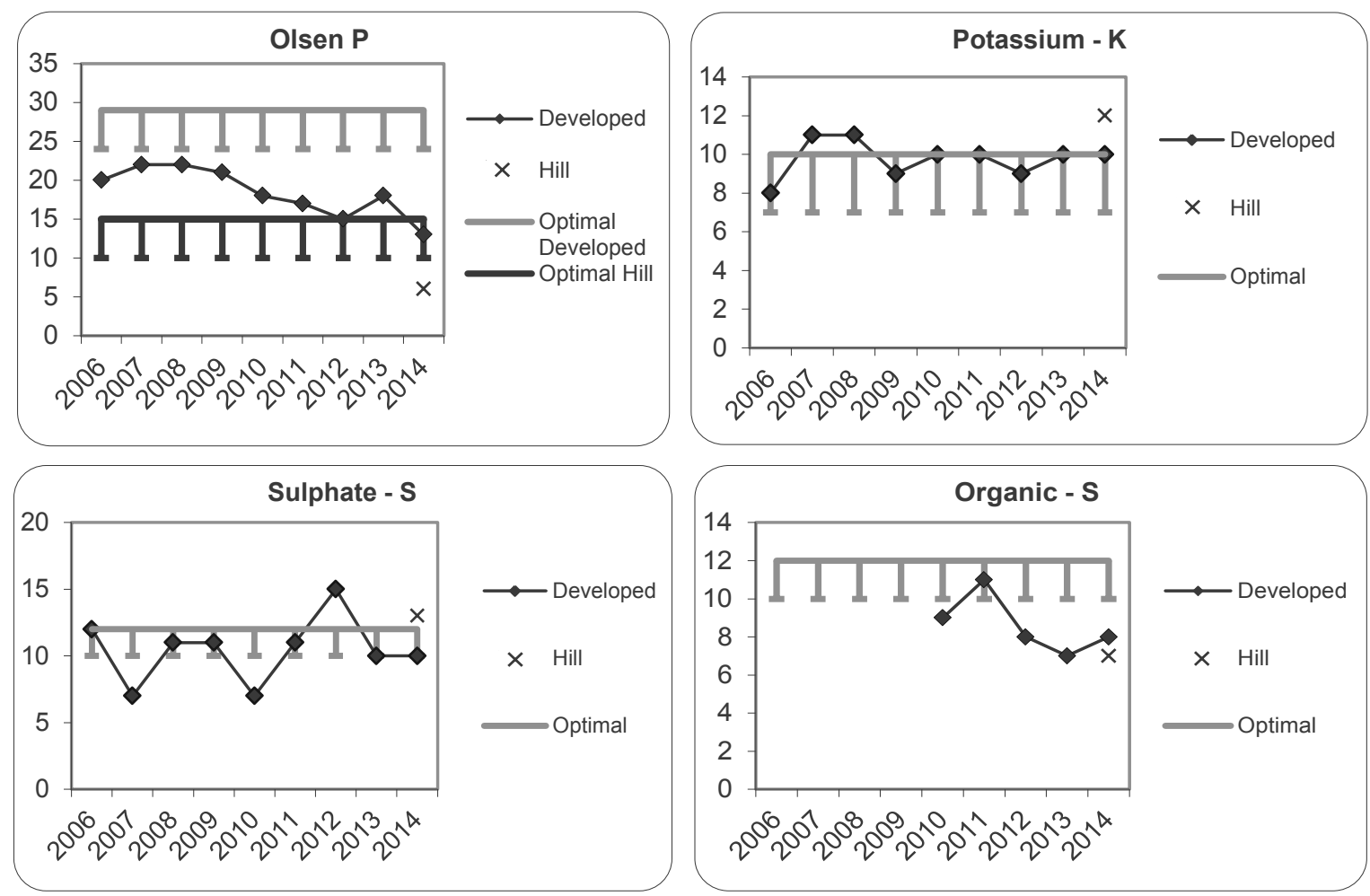

Figure 4 Changes in soil Olsen P ( $\mu \mathrm{g} / \mathrm{ml}$ soil), soil K (MAF Quick Test Units), and sulphate sulphur-S and organic S ( $\mu \mathrm{g} / \mathrm{g}$ in soil) on two blocks over time, relative to the optimal ranges (grey-scale bands), on a sheep and beef farm in west Southland.
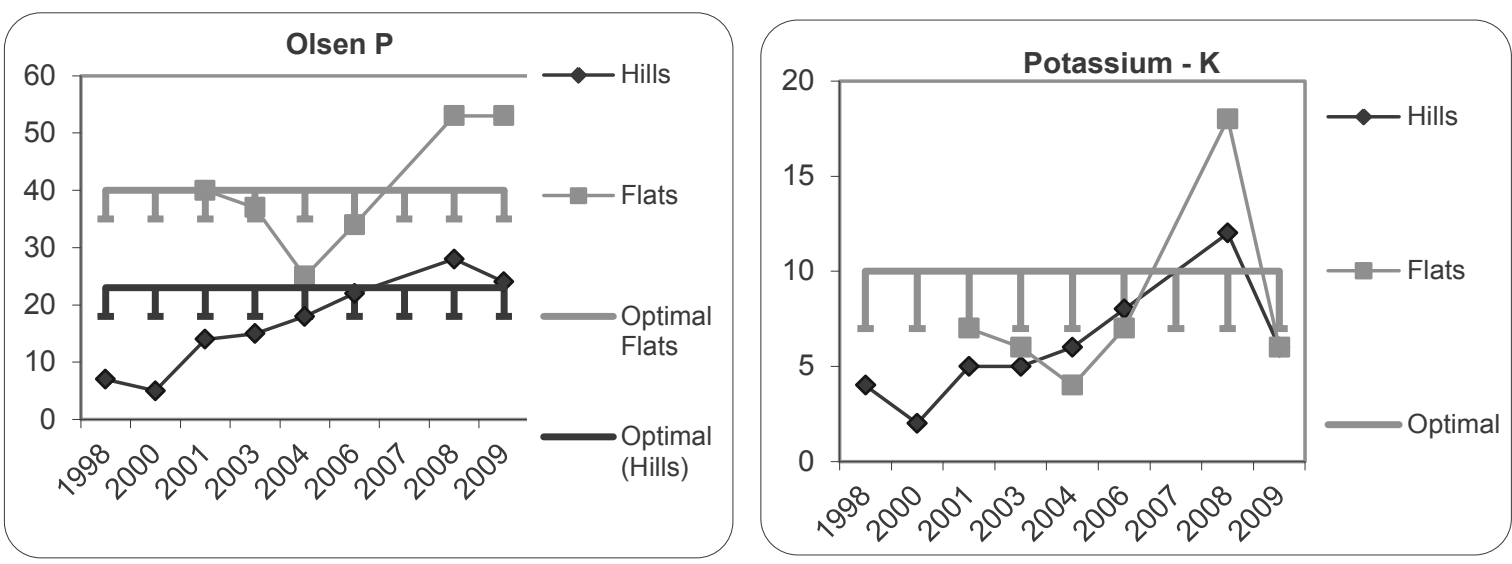

Figure 5 Changes in soil Olsen P ( $\mu \mathrm{g} / \mathrm{ml}$ soil) and soil K (MAF Quick Test Units), over time, relative to the optimal ranges (grey-scale bands), on a sheep and beef farm in the King Country.

deficiency. A capital $\mathrm{P}$ and S program was recommended and the predicted increases in pasture production were estimated to be $20-30 \%$.

\section{Sheep and beef}

This sheep and beef farm is located in the King Country on sedimentary soils (hills, $\mathrm{pH}$ 5.5) and on pumice flats ( $\mathrm{pH}$ 5.9). The farm is best described as being in Beef + Lamb land class 4 . It has an average stocking rate of 12 su/ha and a gross margin of \$1 300/ha.
This farm was first visited in 2004 and at this time P and $\mathrm{K}$ were deficient as indicated below (Figure 5). All the other nutrient levels and the soil $\mathrm{pH}$ were within or above the optimal ranges.

A capital $\mathrm{P}$ and $\mathrm{K}$ fertiliser program, together with a maintenance input of S, was commenced in 2004 and cost about \$25/su. Once the soil $\mathrm{P}$ and $\mathrm{K}$ levels reached the optimal ranges a maintenance fertiliser program for $\mathrm{P}, \mathrm{K}$ and $\mathrm{S}$ was commenced (costing about $\$ 10 / \mathrm{su}$ ). The predicted increase in the annual pasture production 
from the capital fertiliser program was about $20 \%$. As a result of the capital fertiliser program the measured farm production ( $\mathrm{kg}$ product/ha) increased by about $25 \%$.

\section{Sheep and beef}

This farm was unique. Located in the East Coast in Hawkes Bay (Beef + Lamb land class 3, stocking rate $8 \mathrm{su} / \mathrm{ha}$, gross margin $\$ 800 / \mathrm{ha})$. The historical soil $\mathrm{P}$ and $\mathrm{K}$ tests data indicated optimal levels (Figure 6). The soil S data were confusing. The sulphur S levels were extremely variable and organic $S$, which was only measured in one year, suggested suboptimal. The soil $\mathrm{pH}$ levels were, however, low and below the economic optimal range (5.5-5.6) for aerial spread lime.

Based on this information the decision was made to withhold inputs of $\mathrm{P}$ and $\mathrm{K}$ for 2 years and divert the fertiliser dollars into a liming program (3 tonnes/ha). Sulphur (fine elemental S) was also added to the lime. Once this capital liming program was completed it was planned to return to a maintenance $\mathrm{P}, \mathrm{K}$ and $\mathrm{S}$ program.

The predicted increase in annual pasture production from the liming program was estimated to be about $7-8 \%$ and the net present value (profit allowing for inflation) of the investment over the duration of the one-off liming effect ( 6 years) was about $\$ 150 /$ ha.

\section{Discussion}

If it is assumed that the agKnowledge Ltd clients are representative of the sheep and beef sector, then the evidence presented above indicates that there is a large potential to increase soil fertility and hence the productivity of hill country farms in New Zealand by the application of the current knowledge regarding soil fertility and pasture nutrition.

The calculations of the economic Olsen $\mathrm{P}$ ranges were based on Overseer 3 (Metherell 1994), which was developed in the early 1990s. This software is now owned by the fertiliser industry and is being updated, it is assumed to take into account the key findings from the recent reviews. The upgraded software will only be available to industry personnel (A.H.C. Roberts pers. comm.)

agKnowledge Ltd with mathematical input from Massey University (Albany Campus) and financial support from agMardt, has developed, and are currently testing, new dynamical models (as distinct from mechanistic models) for $\mathrm{P}, \mathrm{K}$ and $\mathrm{S}$ which will allow consultants to examine economic outcomes (Net Present Value and Internal Rate of Return) from any given fertiliser policy, based on the predicted changes in pasture and hence animal production. This modelling approach requires fewer input variables than is required to run mechanistic models and allows the user to readily determine the most profitable combination of nutrients
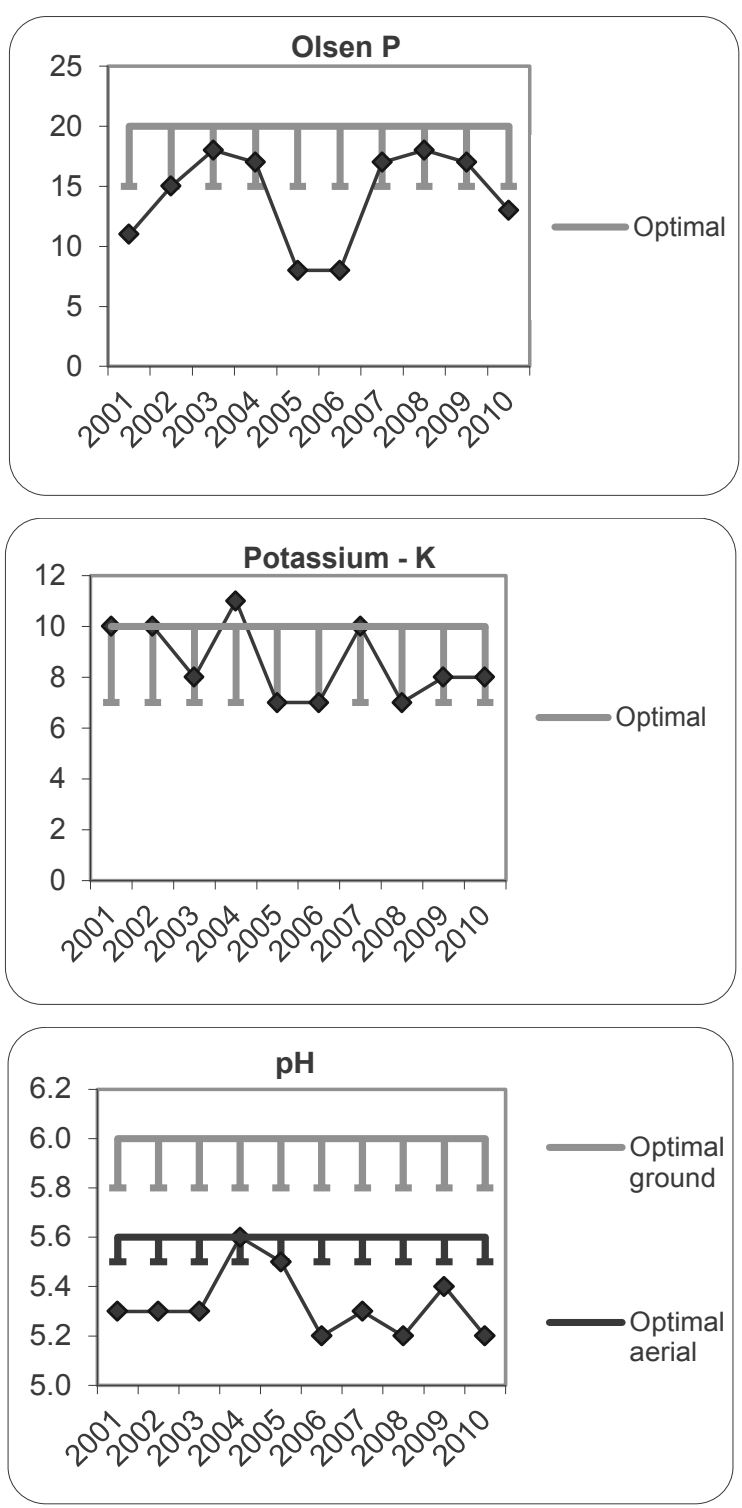

Figure 6 Changes in soil Olsen $\mathrm{P}(\mu \mathrm{g} / \mathrm{ml}$ soil), soil $\mathrm{K}$ (MAF Quick Test Units), and soil pH on a sheep and beef farm on the East Coast over time, relative to the optimal ranges (grey-scale bands).

(P, K and S) to optimise the long-term farm profitability based on the goals on a given farm.

It is an annualized model and takes a long-term perspective (10-20 years). It is designed as an expert system and typically the consultant (expert) would run the model initially to set-up the farm fertiliser plan, based on the farm's potential and the farmer's production and economic goals. Updates could follow if there where major changes to the farm policies or economic circumstances.

One of the important outputs from the model is the predicted changes in pasture production (increases or decreases year by year) for a given fertiliser program. 
This output could be used to develop or refine stock policies, using the farm management software Farmax.

\section{REFERENCES}

Edmeades, D.C.; Pringle, R.M.; Mansell, G.P.; Shannon, P.W.; Ritchie, J.; Stewart, K.M. 1985. Effects of lime on pasture production on soils in the North Island of New Zealand: Description of a lime recommendation scheme. New Zealand Journal of Agricultural Research 13: 47-58.

Edmeades, D.C.; Thorrold, B.S.; Roberts, A.H.C. 2005. The diagnosis and correction of sulphur deficiency and the management of sulphur requirements in New Zealand pastures. Australian Journal of Experimental Agriculture 45: 1205-1223.

Edmeades, D.C.; Metherell, A.K.; Waller, J.; Roberts, A.H.C.; Morton, J. D. 2006. Defining the relationships between pasture production and soil $\mathrm{P}$ and the development of a dynamic P model for New Zealand pastures. New Zealand Journal of Agricultural Research 49: 200-222.

Edmeades, D. C.; Morton, J. D.; Waller, J.; Metherell, A.K.; Roberts, A.H.C.; Carey, J. 2010. The diagnosis and correction of potassium deficiency in New Zealand pastures: a review. New Zealand Journal of Agricultural Research 53: 151-173.

Metherell, A.K. 1994. A model for phosphate fertiliser requirements for pastures - incorporating dynamics and economics. pp. 18-37. In: The efficient use of fertilisers in a changing environment: reconciling productivity and sustainability. Eds. Currie, L.D.; Loganathan, P. Proceedings of a workshop. Occasional Report No 7. Massey University. 